\title{
Effect of Polymerization Time and Shade on the Depth of Cure of Nano-Hybrid Resin Composites
}

\author{
Roula Safouh Al-Bounni ${ }^{4}$ \\ ${ }^{1}$ Restorative and Aesthetic Specialist, Riyadh Elm University, Riyadh, \\ Saudi Arabia \\ 2 Private Practice, Aqua Dental Express, Stockholm, Sweden \\ ${ }^{3}$ Restorative and Aesthetic Consultant, King Fahd Hospital, Ministry \\ of Health, Jeddah, Saudi Arabia \\ ${ }^{4}$ Department of Restorative and Endodontics, Riyadh Elm \\ University, Riyadh, Saudi Arabia
}

Noha Abdullah Bin Jabr ${ }^{1}$ Wacim Nassouh Al-Saidi ${ }^{2}$ Ibtessam Abdullah Bin Jabr ${ }^{3}$

\begin{abstract}
Address for correspondence Noha Abdullah Bin Jabr, Riyadh Elm University, An Namudhajiyah 11564, Saudi Arabia

(e-mail: nuha.al-jabr@hotmail.com).
\end{abstract}

Eur Dent Res Biomater J 2021;2:28-33.

\begin{abstract}
Objective The effect of polymerization time and resin shade on the depth of cure (DOC) of two nano-hybrid resin composites (Filtek Z250 XT and IPS Empress Direct) was evaluated and compared.

Materials and Methods Sixty specimens were prepared from two shades (A1 and A3) of the resin composites. The specimens were allocated into two groups that were further divided into three subgroups depending on the polymerization time $(20,40$, and $60 \mathrm{sec} ; n=5)$. After that, the DOC was evaluated by calculating the polymerized part of the specimen's thickness to the nearest $(0.01 \mathrm{~mm})$ using a high-accuracy micrometer. Each specimen was measured three times, and the corresponding mean reading (in $\mathrm{mm}$ ) was divided by two to obtain the DOC. The data were analyzed using SPSS software, version 20. Descriptive statistics followed by three-way analysis of variance was applied. Multiple comparisons were made using Scheffe post hoc tests $(\alpha=0.05)$. Results Filtek Z250XT-A1-60sec presented with the greatest DOC $(7.42 \pm 0.47 \mathrm{~mm})$, and the lowest DOC was obtained with IPS Empress-A3-20sec $(2.31 \pm 0.21 \mathrm{~mm})$. The mean DOC of Filtek Z250 XT and IPS Empress Direct resin composites were $6.18 \mathrm{~mm}$ and $3.59 \mathrm{~mm}$, respectively. Statistically significant $(p<0.05)$ difference was observed between the resin composites. The interaction between independent factors, namely composites, resin shade, and polymerization time, revealed that interaction between them contributed significantly to the DOC $(p \leq 0.05)$. However, the interaction between

- Keywords

- resin composites

- curing depth

- polymerization

- aesthetics

resin shade and the polymerization time was insignificant $(p=0.148)$.

Conclusion Filtek Z250 XT demonstrated greater DOC than IPS Empress Direct resin composite. An increase in polymerization time significantly enhanced the DOC of the resin composites irrespective of the resin shade. Regardless of the resin composite tested, DOC was lower for darker shades (A3).
\end{abstract}

DOI https://doi.org/

10.1055/s-0041-1726169.
C 2021. European Dental Research and Biomaterials Journal. This is an open access article published by Thieme under the terms of the Creative Commons Attribution-NonDerivative-NonCommercial-License, permitting copying and reproduction so long as the original work is given appropriate credit. Contents may not be used for commercial purposes, or adapted, remixed, transformed or built upon. (https://creativecommons.org/licenses/by-nc-nd/4.0/).

Thieme Medical and Scientific Publishers Pvt. Ltd. A-12, 2nd Floor, Sector 2, Noida-201301 UP, India 


\section{Introduction}

Demand for aesthetic restorative materials has led to the development of resin-based composites (RBCs). The technological advancement in material composition and properties has made RBCs a favorable material over other restorative materials in present-day aesthetic dentistry. ${ }^{1}$ Apart from their aesthetic properties, they also present with good handling characteristics and clinical durability. ${ }^{2}$ However, some of the resin composites' constituents may degrade over time, affecting the resin composite's durability, thereby compromising the aesthetic outcome obtained initially. ${ }^{3}$ Furthermore, the resin composites' contraction (by 1.5-5\%) following polymerization causes unrelieved stresses. Eventually, it could result in clinical complications including secondary caries, microleakage, the formation of a marginal gap, irritation of the pulp, cracks in the sound tooth structure, and possible tooth loss. ${ }^{4-7}$

The depth of cure (DOC) of resin composites is considered an important parameter because of their ability to assess the clinically relevant quality of cure. It has been the topic of extensive laboratory research. ${ }^{5}$ Nevertheless, controversies do exist regarding the polymerization of resin composite. Incomplete or inadequate polymerization of resin composite can induce wear and early degradation of the restorations, decreased functional ability, and ultimately restorative failure.

The DOC of resin composite is determined by size and thickness of filler particle, filler loading, and polymerization initiator concentration. ${ }^{8}$ The factors affecting the DOC are the particle size of the resin composite, light intensity, polymerization time, and shade of the resin composites. ${ }^{9}$

In 1988, the International Organization for Standardization (ISO) established a technique for determining the maximum incremental thickness of resin composite that was officially entitled as "ISO 4049; Depth of Cure." ${ }^{10}$ Accordingly, a cylindrical mold is filled with the resin composite to be evaluated, followed by light-curing, and forcing the specimen out of the mold. The uncured (soft) resin is then "scraped away" with a plastic instrument so that only the hard cylindrical specimen is available for measurement. Finally, the full length of the cured specimen is calculated and the readings obtained are divided by two. The reason behind the division factor is that not all the obtained specimen is ideally cured. As per the recent "ISO 2019:4049; Depth of Cure" standard, it is necessary for a material to demonstrate with a minimum DOC of $1.5 \mathrm{~mm}$ when cured as per the manufacturer's recommendation. ${ }^{11}$

Therefore, in the present study, the effect of polymerization time and resin shade on the DOC of two nano-hybrid resin composites (Filtek Z250 XT and IPS Empress Direct) was evaluated and compared. The null hypotheses tested was: (1) the DOC of the two resin composites is comparable irrespective of polymerization time and shade, and (2) different polymerization time (20,40, and $60 \mathrm{sec})$ and shade (A1 and A3) have an insignificant effect on the DOC of the resin composite.

\section{Materials and Methods}

This laboratory study determined the DOC of two composite resins according to the method described in the international standards (ISO 4049:2019). ${ }^{11,12}$ - Table 1 details the materials and their composition used for the study.

\section{Specimen Preparation}

The samplesize for the presentstudy was estimated by G*Power software (version 3.1.9.3; Heinrich-Heine-Universität Düsseldorf, Germany). The sample size at the level of sight $(\alpha=0.05)$, estimated standard deviation (SD) $=0.32,0.6$ effect size, and 0.8 power required a minimum of five specimens $(n=5)$ per group. Fifteen cylindrical specimens (height, $8 \mathrm{~mm}$ and diameter, $6 \mathrm{~mm}$ ) were fabricated from A1 and A3 shades of the two resin composite materials using a stainless steel mold. These 15 specimens were further subdivided into three groups $(n=5)$ depending on the time the specimens are light-cured (20,40, and $60 \mathrm{sec})$. Accordingly, 60 specimens in total were acquired from 2 shades of the resin composite materials. The specimen distribution is shown in - Fig. 1.

The open-end mold was placed on a transparent strip (Hawe; Kerr Dental, United States) fixed onto a flat glass slab for fabricating the specimens. The resin was packed and condensed into the mold using a hand instrument, and the top end of the mold was closed with another strip and manually compressed using a microscopic slide. This ensured uniform distribution of the resin composite and flushing out any excess material from the mold. The microscopic glass slide on the top end was removed, and the resin composites were polymerized using visible light-curing unit (Elipar FreeLight 2, 3M ESPE, Germany). The curing unit was positioned above the transparent strip on the mold aperture at zero distance. The light-curing unit was operated with a power density of 1,200 to $1,500 \mathrm{~mW} / \mathrm{cm}^{2}$ and a wavelength

Table 1 Resin composites used in the study

\begin{tabular}{|c|c|c|}
\hline Material & Composition & $\begin{array}{l}\text { Filler load } \\
\text { (vol \%) }\end{array}$ \\
\hline $\begin{array}{l}\text { Filtek Z250 } \\
\text { XT ( } 3 \mathrm{M} \text { ESPE, } \\
\text { St. Paul, } \\
\text { Minnesota, } \\
\text { United States): } \\
\text { shades A1 and } \\
\text { A3 }\end{array}$ & $\begin{array}{l}\text { - Organic matrix: bis-GMA, } \\
\text { UDMA, bis-EMA, PEGDMA, } \\
\text { TEGDMA } \\
\text { - Inorganic matrix: Zirconia/ } \\
\text { Silica (0.1-10 microns), } \\
20 \text { nm surface-modified } \\
\text { silica particles }\end{array}$ & $60-68$ \\
\hline $\begin{array}{l}\text { IPS Empress } \\
\text { Direct (Ivoclar } \\
\text { Vivadent } \\
\text { AG, Schaan, } \\
\text { Liechtenstein): } \\
\text { shades A1 and } \\
\text { A3 }\end{array}$ & $\begin{array}{l}\text { Organic matrix: bis-GMA, } \\
\text { UDMA, TCDMA } \\
\text { - Inorganic matrix: barium } \\
\text { glass, ytterbium trifluoride, } \\
\text { mixed oxide, silicon dioxide, } \\
\text { and copolymer }\end{array}$ & $52-59$ \\
\hline
\end{tabular}

Abbreviations: bis-EMA, bisphenol ethyl methacrylate; bis-GMA, bisphenol glycol dimethacrylate; PEGDMA, polyethylene glycol dimethacrylate; TCDMA, tricyclodocane dimethanol dimethacrylate; TEGDMA, triethylene glycol dimethacrylate; UDMA, urethane dimethacrylate. 


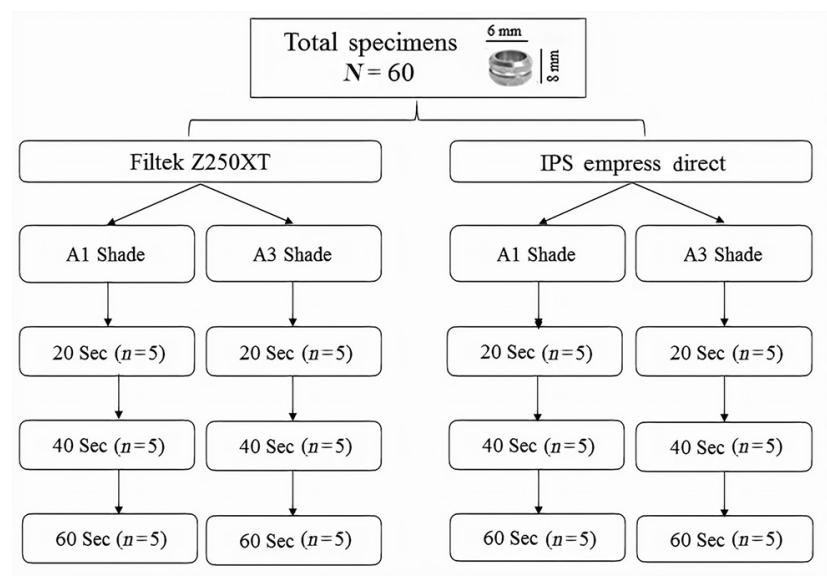

Fig. 1 Specimen distribution.

range of 420 to $480 \mathrm{~nm}$. According to the manufacturer's protocol, the curing time for the tested resin composites is $20 \mathrm{sec}$ for a thickness of $2.5 \mathrm{~mm}$.

\section{Depth of Cure Measurements}

The scraping technique for depth of cure (DOC) measurements was followed as per the ISO standards. ${ }^{11}$ The uncured material at the lower end of the mold was partially removed after polymerization to make room for inserting the attachment rod fitted with the mold and force the specimen out. Once the specimen was retrieved from the mold, the uncured material was gently scraped off using a plastic instrument applying light pressure. The specimen's remaining cured material was cleaned with alcohol-treated gauze to ensure complete removal of uncured resin composite. After that, the DOC was calculated by measuring the thickness of the polymerized portion of the resin specimen to the nearest $(0.01 \mathrm{~mm})$ with a high-accuracy digital micrometer (Mitutoyo Corp., Kawasaki, Japan). Each specimen was measured three times, and the corresponding mean reading (in $\mathrm{mm}$ ) was divided by two to obtain the DOC.

\section{Statistical Analysis}

All the data were analyzed using IBM-SPSS software (IBM Corp.; Armonk, NY, United States), version 20. The data were tested for normality distribution using the Shapiro-Wilk test. Parametric tests were applied as the pooled data followed a normal and homogeneous distribution. For all the groups, descriptive statistics (mean $\pm \mathrm{SD}$ ) of the DOC were determined. Three-way analysis of variance (ANOVA) was applied to pertain to factors, namely resin composites, shades, and polymerization time. Multiple comparisons between the groups were tested by Scheffe post hoc analysis $(\alpha=0.05)$.

\section{Results}

The mean DOC of the study groups is presented as $\boldsymbol{-}$ Fig. $\mathbf{2}$. Filtek Z250 XT-A1-60sec presented with the greatest DOC $(7.42 \pm 0.47 \mathrm{~mm})$, and the lowest DOC was obtained with IPS Empress-A3-20sec $(2.31 \pm 0.21 \mathrm{~mm})$. For the Filtek Z250 XT,

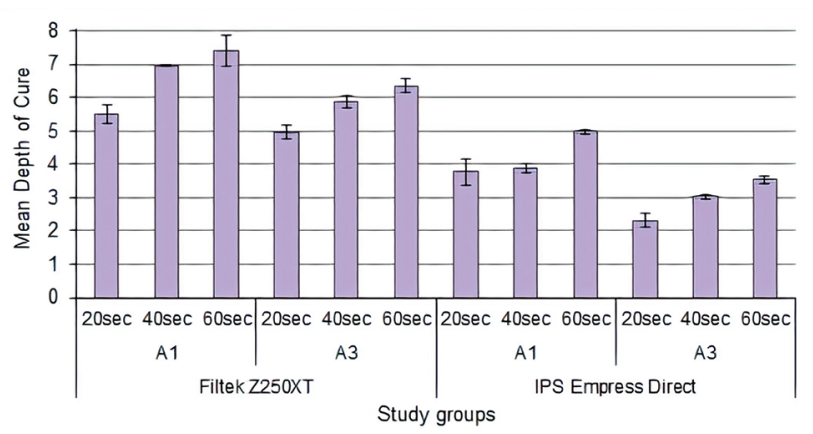

Fig. 2 Mean ( \pm standard deviation) depth of cure of the resin composites.

the DOC ranged from $5.5 \pm 0.27$ to $7.42 \pm 0.47 \mathrm{~mm}$ for A 1 shade, and from $4.95 \pm 0.21$ to $6.36 \pm 0.21 \mathrm{~mm}$ for A3 shade. Similarly, for IPS Empress Direct, the DOC ranged from $3.77 \pm 0.38$ to $4.98 \pm 0.21 \mathrm{~mm}$ for A1 shade, and from $2.31 \pm 0.21$ to $3.54 \pm$ $0.13 \mathrm{~mm}$ for A3 shade.

Comparison of the effects of independent factors analyzed separately is presented in - Table 2 .

The mean DOC of Filtek Z250 XT and IPS Empress Direct resin composites were $6.18 \mathrm{~mm}$ and $3.59 \mathrm{~mm}$, respectively. The difference in DOC between the resin composites was statistically significant $(p<0.05)$. DOC of A1 shade $(5.42 \mathrm{~mm})$ was more significant for the resin shades than A3 shade $(4.35 \mathrm{~mm})$. Scheffe post hoc test revealed a difference in the DOC between the resin shades that was statistically significant $(p<0.05)$. Similarly, the comparison of DOC regarding polymerization time showed a significant difference between different polymerization times $(p<0.05)$. The DOC of resin composites polymerized for $60 \mathrm{sec}(5.58 \mathrm{~mm})$ was more significant than the resin composites polymerized for $40 \mathrm{sec}(4.93 \mathrm{~mm})$ and $20 \mathrm{sec}(4.14 \mathrm{~mm})$, irrespective of the shade and resin composites.

Three-way ANOVA for the interaction between the independent factors, namely resin composites, shade, and polymerization time, is presented in - Table $\mathbf{3}$. The interaction between resin composite and shade showed significant effect on DOC ( $F=7.947 ; p=0.007)$. Similarly, the interaction between resin composite and polymerization time showed significant effect on DOC $(F=13.148 ; p<0.001)$. However, the interaction between resin shade and polymerization time did not affect the DOC ( $F=1.985 ; p=0.148)$. Overall, the interaction between the independent factors (resin composites, shade, and polymerization time) revealed that interaction between the factors had a statistically significant effect on the $\operatorname{DOC}(F=7.429 ; p=0.002)$.

\section{Discussion}

Complete curing of resin composite is an essential requirement for the long-term success of the intraoral restorations. Therefore, it is of utmost importance to focus on the DOC of the resin composites, considering the frequent introduction of new generations and various resin composites into the routine clinical practice. Furthermore, all these resin composites should meet the ISO 2019/4049 standards for DOC. 
Table 2 Mean comparison of the independent factors

\begin{tabular}{|l|l|l|l|l|}
\hline Factors & Groups & Mean & $\begin{array}{l}\text { Standard } \\
\text { difference }\end{array}$ & -Value \\
\hline \multirow{2}{*}{$\begin{array}{l}\text { Composite } \\
\text { type }\end{array}$} & $\begin{array}{l}\text { Filtek } \\
\text { Z250 XT }\end{array}$ & 6.18 & 0.43 & $0.000^{\mathrm{a}}$ \\
\cline { 2 - 4 } & $\begin{array}{l}\text { IPS } \\
\text { Empress } \\
\text { Direct }\end{array}$ & 3.59 & 0.43 & \\
\hline \multirow{2}{*}{ Shade } & $\mathrm{A} 1$ & 5.42 & 0.43 & \multirow{2}{*}{$0.000^{\mathrm{a}}$} \\
\cline { 2 - 4 } & $\mathrm{A} 3$ & 4.34 & 0.43 & \multirow{2}{*}{$0.000^{\mathrm{a}}$} \\
\hline \multirow{2}{*}{$\begin{array}{l}\text { Polymerization } \\
\text { time }\end{array}$} & $20 \mathrm{sec}$ & 4.13 & 0.53 & \\
\cline { 2 - 4 } & $40 \mathrm{sec}$ & 4.93 & 0.53 & \\
\cline { 2 - 4 } & $60 \mathrm{sec}$ & 5.58 & 0.53 & \multicolumn{2}{|c|}{} \\
\hline
\end{tabular}

aStatistically significant $(p<0.05)$; Scheffe post hoc comparison.

Advancement in the filler particle size through enhanced milling and grinding methods have resulted in submicron (nano-hybrid) resin composites. These composites' average particle size is about 0.4 to $1 \mu \mathrm{m}$ and contain finely ground filler glasses and nano-filler in a prepolymerized filler form. ${ }^{13}$ These composites are commonly called universal composites, and since they possess excellent mechanical properties and polishing ability, they can be used for most anterior and posterior restoration. ${ }^{14}$ Additionally, these resin composites have the greatest DOC, followed by condensable, hybrid, and flowable composites under the same polymerization parameters. ${ }^{15}$ Consequently, the present laboratory study was conducted to evaluate and compare the effect of polymerization time and resin shade on the DOC of two (Filtek Z250 XT and IPS Empress Direct) nano-hybrid resin composites. The present study's outcome suggested a rejection of both hypotheses as the tested composites' DOC was not comparable. Different polymerization time and resin shade had a statistically significant effect on the DOC of the tested composites. A similar outcome was also reported in previous studies evaluating the DOC of resin composites. ${ }^{16,17}$

In the current study, all the specimens irrespective of the material, shade, and polymerization time met the ISO standard DOC requirement of $1.5 \mathrm{~mm} .{ }^{18}$ The scraping technique recommended by the ISO standard 4049 was employed to calculate the DOC. This approach's primary benefit is that it is simple to perform in any dental clinic within a short period, and it does not require advanced equipment. According to this technique, the uncured material at the lower end of the specimen is scraped off to remove the soft uncured portion. The remaining length of the hardened portion is measured and divided by two. This is because the resin composite's hardness at the lower end of the remaining specimen is almost 0 and is considered inadequately cured for clinical situations. It has been demonstrated that at $50 \%$ of the length of the cylindrical specimen, the hardness is about $80 \%$ at the top of the specimen, and, therefore, a top-bottom to top-surface hardness ratio of $80 \%$ of a reference specimen is considered adequately cured by most researchers. ${ }^{18,19}$ Furthermore, some amount of residual monomers and other reactive oxygen
Table 3 Three-way analysis of variance for the effect of interaction between resin composites, shade, and polymerization time on the depth of cure

\begin{tabular}{|c|c|c|c|c|}
\hline Factors & $\mathrm{DF}$ & $\begin{array}{l}\text { Mean } \\
\text { square }\end{array}$ & $F$-value & $p$-Value \\
\hline Resin composite, ${ }^{a}$ shade & 1 & 0.449 & 7.947 & $0.007^{a}$ \\
\hline $\begin{array}{l}\text { Resin composite, }{ }^{\mathrm{a}} \text { polym- } \\
\text { erization time }\end{array}$ & 2 & 0.743 & 13.148 & $0.000^{\mathrm{a}}$ \\
\hline $\begin{array}{l}\text { Shade, }{ }^{a} \text { Polymerization } \\
\text { time }\end{array}$ & 2 & 0.112 & 1.985 & 0.148 \\
\hline $\begin{array}{l}\text { Resin composite, }{ }^{\mathrm{a}} \text { shade, }{ }^{\mathrm{a}} \\
\text { polymerization time }\end{array}$ & 2 & 0.420 & 7.429 & $0.002^{\mathrm{a}}$ \\
\hline
\end{tabular}

Note: DF refers to the degrees of freedom (N-1); F-value refers to the variation between specimen means/variation within the specimens. aStatistically significant $(p \leq 0.05)$.

species (ROS) are released into the oral cavity even from a well-cured resin composite specimen. Therefore, it is rational to assume that more residual monomers and ROS would elute from the bottom of the poorly cured or uncured resin composite. Such eluted compounds can irritate soft tissues and pulp, promoting bacterial growth and encouraging toxic/allergic reactions. ${ }^{20-22}$ Clinically, achieving adequate polymerization at the bottom surface of each incremental layer used to build up the restoration is crucial.

The decrease in curing-light intensity with material depth is one of the common problems encountered with a visible light-cured dental restorative material. This is because less camphorquinone is activated as usable curing wavelengths are attenuated in the resin. ${ }^{23}$ The degree and capability of the polymerization process of a resin composite activated by visible light is a function of multiple parameters. Accordingly, the type and relative quantity of monomers, the composition of the filler, initiator/catalyst system, resin shade and translucency, temperature during polymerization, intensity and wavelength of curing light, and polymerization time contribute to the polymerization of the resin composites. ${ }^{18,24-28}$

In line with the earlier statement, the shade is a relevant parameter affecting the resin composite's DOC. ${ }^{19}$ In the present study, to assess the composite shade effect on the DOC for the tested resin composites, two resin shades (lighter A1 and darker A3) were included. It was found that the "light shades" (A1) irrespective of the resin composite had greater DOC compared to "darker shades" (A3). This outcome agrees with the previous studies. ${ }^{16,29-33}$ Koupis et al ${ }^{32}$ compared A2 and A4 resin shades polymerized for $40 \mathrm{sec}$ and found greater DOC for A2 samples. Similarly, Moore et $\mathrm{al}^{20}$ compared B1, A3, and D3 resin shades and found improved DOC for the lighter resin shade (B1). Rodriguez et $\mathrm{al}^{17}$ evaluated the DOC of two shades (light and dark) of four resin composites and found higher DOC for light-shaded resin than resin with dark shades. It is understood that different shades of resin composites contain different type and quantity of color pigments. The lower DOC of the dark-shade resin composite could be related to the increased absorption of the light by the pigments, resulting in reduced penetration of light into the resin material. ${ }^{34}$ 
The other variable in the present study was the polymerization time of 20,40 , and $60 \mathrm{sec}$ for both resin composites and shades. All the specimens irrespective of the material and shade were passing the ISO 2019/4049 standard requirements. Furthermore, the DOC of both resin composites increased with an increase in polymerization time. According to the manufacturer (3M ESPE for Filtek Z250 XT and Ivoclar Vivadent for IPS Empress Direct), the recommended polymerization time is $20 \mathrm{sec}$ with an LED-light-emitting diode-light source. The polymerization time is an essential parameter in routine clinical practice, and many clinicians would follow an ideal $20 \mathrm{sec}$ polymerization time to reduce the treatment duration. Furthermore, polymerization time alone is a crucial factor contributing to DOC. Nevertheless, as light passes through the depth of the composite, power density is greatly reduced thus decreasing the efficacy of polymerization. ${ }^{23}$ The resin composite that is not adequately polymerized will affect the pulpal tissues due to leaching of uncured resin components, and present with suboptimal properties in relation to composites' strength, wear resistance, and water sorption. ${ }^{7}$ Therefore, it is of utmost importance to follow a longer irradiation time to ensure a quality procedure contributing to the optimal curing of the inner portion of the resin composite..$^{35}$

Among the resin composites tested, Filtek Z250 XT demonstrated greater DOC than IPS Empress Direct resin composite. The DOC of a resin composite depends on the filler particle size that constitutes the composites. As the filler particles approach the curing light's wavelength, the light emanating from the source is gradually scattered within the composite. This would result in less light being absorbed through the composite. Therefore, light trying to penetrate small composite particles has a more challenging task to penetrate the material's deeper regions. This requires greater irradiances or exposure times to cure the composite adequately. This possibly explains the greater DOC concerning Filtek Z250 XT made of large particle size compared to IPS Empress Direct. This is in accordance with the previous study ${ }^{36}$ concluding that composites with large particle size are less influenced by light scattering and therefore present with greater DOC compared to small composite particles. The second explanation for greater DOC concerning Filtek Z250 XT is the filler loading. A composite with heavy filler and large particle size has a greater DOC. ${ }^{37}$ Filtek Z250 XT is loaded with 60 to $68 \%$ filler by volume, and IPS Empress Direct has 52 to 59\% filler loading by volume ${ }^{38}$ Furthermore, the difference in DOC of the resin composites is also attributed to the resins' chemical formulations. ${ }^{39}$

Future studies should be directed in relating the DOC with the mechanical properties of the tested resin composites. Furthermore, the effect of different curing units on DOC should be evaluated.

\section{Conclusion}

1. All the specimens, regardless of the composite type, shade, and polymerization time, met the ISO standard for DOC.

2. Filtek Z250 XT demonstrated greater DOC than IPS Empress Direct resin composite ( $p$ \&\#x2264; 0.05).
3. An increase in polymerization time resulted in a significant increase in the resin composites' DOC irrespective of the shade ( $p \& \# \times 2264 ; 0.05)$.

4. The dark shade composite, A3, demonstrated lower DOC regardless of the resin composites tested.

\section{Conflict of Interest}

None declared.

\section{References}

1 Hickel R, Heidemann D, Staehle HJ, Minnig P, Wilson NH; German Scientific Association for Operative Dentistry. European Federation of Conservative Dentistry. Direct composite restorations: extended use in anterior and posterior situations. Clin Oral Investig 2004;8(2):43-44

2 Mikhail SS, Schricker SR, Azer SS, Brantley WA, Johnston WM. Optical characteristics of contemporary dental composite resin materials. J Dent 2013;41(9):771-778

3 Dantas D, Mathias-Santamaria I, Borges A, Torres C, Caneppele T. Effects of artificial accelerated aging on the optical properties of resin composites. Biosci J 2018;34(2):505-513

4 Soares CJ, Faria-E-Silva AL, Rodrigues MP, et al. Polymerization shrinkage stress of composite resins and resin cements - What do we need to know? Braz Oral Res 2017;31(suppl 1) :e62

5 Tabassum S, Hameed MH, Khan FR. Comparison of the depth of cure of flowable composites polymerized at variable increment thicknesses and voltages: an in vitro study. Contemp Clin Dent 2019;10(2):220-225

6 Savadamoorthi K, Priyadharshini S, Sherwood A, Jesudoss $\mathrm{K}$, Kumar V, Christopher A. In vitro analysis and comparison on depth of cure in newer bulk fill composite resin with conventional micro- and nano-hybrid composite resin using two different light sources quartz-tungsten-halogen and light emitting diode with three varying intensities. J Int Oral Health 2017;9(1):12-15

7 Jang JH, Park SH, Hwang IN. Polymerization shrinkage and depth of cure of bulk-fill resin composites and highly filled flowable resin. Oper Dent 2015;40(2):172-180

8 Rouhollahi M, Mohammadibasir M, Talim Sh. Comparative depth of cure among two light-cured core build-up composites by surface Vickers hardness. J Dent (Tehran) 2012;9(3):255-261

9 Li Y, Gao S, Tarimo SA, et al. Influence of tooth thickness on depth of cure and degree of conversion of a photo-activated resin composite irradiated through the tooth. Sci J Res Dentistry. 2017;1(3):50-56

10 Flury S, Hayoz S, Peutzfeldt A, Hüsler J, Lussi A. Depth of cure of resin composites: is the ISO 4049 method suitable for bulk fill materials? Dent Mater 2012;28(5):521-528

11 ISO, International Standard Organization 4049:2019(en). Dentistry-Polymer-Based Restorative Materials. Geneva, Switzerland: ISO; 2019

12 Camargo FSAS, González AHM, Alonso RCB, Di Hipólito V, D'Alpino PHP. Effects of polymerization mode and interaction with hydroxyapatite on the rate of $\mathrm{pH}$ neutralization, mechanical properties, and depth of cure in self-adhesive cements. Eur J Dent 2019;13(2):178-186

13 Gordan VV, Patel SB, Barrett AA, Shen C. Effect of surface finishing and storage media on bi-axial flexure strength and microhardness of resin-based composite. Oper Dent 2003;28(5):560-567

14 Endo T, Finger WJ, Kanehira M, Utterodt A, Komatsu M. Surface texture and roughness of polished nanofill and nanohybrid resin composites. Dent Mater J 2010;29(2):213-223 
15 Jain P, Pershing A. Depth of cure and microleakage with high-intensity and ramped resin-based composite curing lights. J Am Dent Assoc 2003;134(9):1215-1223

16 Sa'di S, Mohammad QAH, Mahdi AG. The effect of shade and curing time on the depth of cure (DOC) in two types of composites, polymerized with a halogen light cure system. Kufa Med J 2010;13(1):178-196

17 Rodriguez A, Yaman P, Dennison J, Garcia D. Effect of light-curing exposure time, shade, and thickness on the depth of cure of bulk fill composites. Oper Dent 2017;42(5):505-513

18 Fan PL, Schumacher RM, Azzolin K, Geary R, Eichmiller FC. Curing-light intensity and depth of cure of resin-based composites tested according to international standards. J Am Dent Assoc 2002;133(4):429-434, quiz 491-493

19 Schattenberg A, Lichtenberg D, Stender E, Willershausen B, Ernst CP. Minimal exposure time of different LED-curing devices. Dent Mater 2008;24(8):1043-1049

20 Moore BK, Platt JA, Borges G, Chu TM, Katsilieri I. Depth of cure of dental resin composites: ISO 4049 depth and microhardness of types of materials and shades. Oper Dent 2008;33(4):408-412

21 Gupta SK, Saxena P, Pant VA, Pant AB. Release and toxicity of dental resin composite. Toxicol Int 2012;19(3):225-234

22 Kurt A, Altintas SH, Kiziltas MV, et al. Evaluation of residual monomer release and toxicity of self-adhesive resin cements. Dent Mater J 2018;37(1):40-48

23 Knezević A, Tarle Z, Meniga A, Sutalo J, Pichler G, Ristić M. Degree of conversion and temperature rise during polymerization of composite resin samples with blue diodes. J Oral Rehabil 2001;28(6):586-591

24 Yoshida K, Greener EH. Effects of coupling agents on mechanical properties of metal oxide-polymethacrylate composites. J Dent 1994;22(1):57-62

25 Shortall AC, Wilson HJ, Harrington E. Depth of cure of radiation-activated composite restoratives-influence of shade and opacity. J Oral Rehabil 1995;22(5):337-342

26 Lovell LG, Newman SM, Bowman CN. The effects of light intensity, temperature, and comonomer composition on the polymerization behavior of dimethacrylate dental resins. J Dent Res 1999;78(8):1469-1476

27 Yap AU. Effectiveness of polymerization in composite restoratives claiming bulk placement: impact of cavity depth and exposure time. Oper Dent 2000;25(2):113-120
28 Quance SC, Shortall AC, Harrington E, Lumley PJ. Effect of exposure intensity and post-cure temperature storage on hardness of contemporary photo-activated composites. J Dent 2001;29(8):553-560

29 AlShaafi MM. Factors affecting polymerization of resin-based composites: a literature review. Saudi Dent J 2017;29(2):48-58

30 Della Bona A, Rosa V, Cecchetti D. Influence of shade and irradiation time on the hardness of composite resins. Braz Dent J 2007;18(3):231-234

31 Faria-E-Silva AL, Fanger C, Nguyen L, Howerton D, Pfeifer CS. Impact of material shade and distance from light curing unit tip on the depth of polymerization of composites. Braz Dent J 2017;28(5):632-637

32 Koupis NS, Vercruysse CWJ, Marks LAM, Martens LC, Verbeeck $\mathrm{RMH}$. Curing depth of (polyacid-modified) composite resins determined by scraping and a penetrometer. Dent Mater 2004;20(10):908-914

33 Shortall AC. How light source and product shade influence cure depth for a contemporary composite. J Oral Rehabil 2005;32(12):906-911

34 Lazarchik DA, Hammond BD, Sikes CL, Looney SW, Rueggeberg FA. Hardness comparison of bulk-filled/transtooth and incremental-filled/occlusally irradiated composite resins. J Prosthet Dent 2007;98(2):129-140

35 Ceballos L, Fuentes MV, Tafalla H, Martínez A, Flores J, Rodríguez J. Curing effectiveness of resin composites at different exposure times using LED and halogen units. Med Oral Patol Oral Cir Bucal 2009;14(1):E51-E56

36 Sobrinho LC, de Lima AA, Consani S, Sinhoreti MA, Knowles JC. Influence of curing tip distance on composite Knoop hardness values. Braz Dent J 2000;11(1):11-17

37 Albers HF, Tooth-Colored Restoratives. Principles and Techniques. 9th edition. London: BC Decker; 2002

38 Kang A, Son SA, Hur B, Kwon YH, Ro JH, Park JK. The color stability of silorane- and methacrylate-based resin composites. Dent Mater J 2012;31(5):879-884

39 David JR, Gomes OM, Gomes JC, Loguercio AD, Reis A. Effect of exposure time on curing efficiency of polymerizing units equipped with light-emitting diodes. J Oral Sci 2007;49(1):19-24 